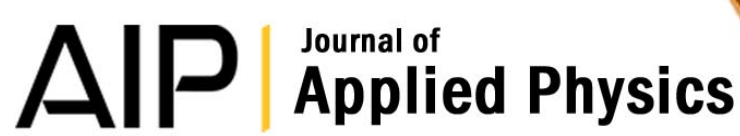

\section{Pump excited state absorption in holmium-doped fluoride glass}

André Felipe Librantz, Stuart D. Jackson, Laércio Gomes, Sidney José Ribeiro, and Younes Messaddeq

Citation: J. Appl. Phys. 103, 023105 (2008); doi: 10.1063/1.2833436

View online: http://dx.doi.org/10.1063/1.2833436

View Table of Contents: http://jap.aip.org/resource/1/JAPIAU/v103/i2

Published by the AIP Publishing LLC.

\section{Additional information on J. Appl. Phys.}

Journal Homepage: http://jap.aip.org/

Journal Information: http://jap.aip.org/about/about_the_journal

Top downloads: http://jap.aip.org/features/most_downloaded

Information for Authors: http://jap.aip.org/authors

\section{ADVERTISEMENT}

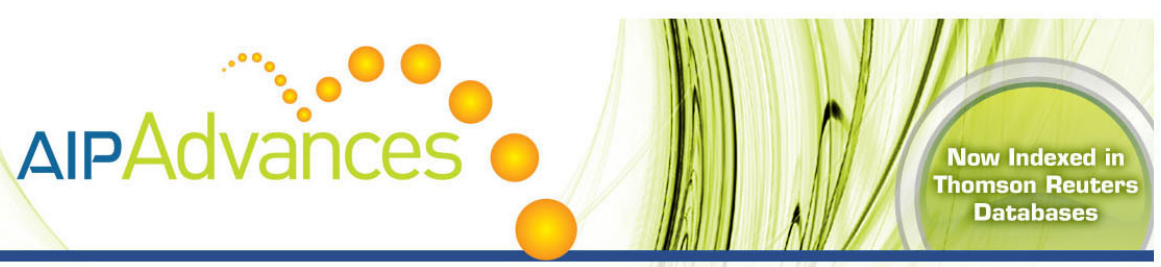

\section{Explore AIP's open access journal: •Rapid publication \\ - Article-level metrics \\ - Post-publication rating and commenting}




\title{
Pump excited state absorption in holmium-doped fluoride glass
}

\author{
André Felipe Henriques Librantz, ${ }^{1,2}$ Stuart D. Jackson, ${ }^{3, a)}$ Laércio Gomes, ${ }^{1}$ \\ Sidney José Lima Ribeiro, ${ }^{4}$ and Younes Messaddeq ${ }^{4}$ \\ ${ }^{1}$ Center for Lasers and Applications, IPEN/CNEN-SP, P.O. Box 11049, São Paulo SP 05422-970, Brazil \\ ${ }^{2}$ Sciences Department, UNINOVE, São Paulo SP 01156-050, Brazil \\ ${ }^{3}$ Optical Fibre Technology Centre, University of Sydney, 206 National Innovation Centre, \\ Australian Technology Park, Eveleigh 1430, Australia \\ ${ }^{4}$ Institute of Chemistry-UNESP, P.O. Box 355, Araraquara SP 14801-970, Brazil
}

(Received 23 September 2007; accepted 21 November 2007; published online 23 January 2008)

The primary excited state absorption processes relating to the ${ }^{5} I_{6} \rightarrow{ }^{5} I_{7} 3 \mu \mathrm{m}$ laser transition in singly $\mathrm{Ho}^{3+}$-doped fluoride glass have been investigated in detail using time-resolved fluorescence spectroscopy. Selective laser excitation of the ${ }^{5} I_{6}$ and ${ }^{5} I_{7}$ energy levels established the occurrence of two excited state absorption transitions from these energy levels that compete with previously described energy transfer upconversion processes. The ${ }^{5} I_{7} \rightarrow{ }^{5} I_{4}$ excited state absorption transition has peak cross sections at $1216 \mathrm{~nm}\left(\sigma_{\text {esa }}=2.8 \times 10^{-21} \mathrm{~cm}^{2}\right), 1174 \mathrm{~nm}\left(\sigma_{\text {esa }}=1 \times 10^{-21} \mathrm{~cm}^{2}\right)$, and $1134 \mathrm{~nm}\left(\sigma_{\text {esa }}=7.4 \times 10^{-22} \mathrm{~cm}^{2}\right)$ which have a strong overlap with the ${ }^{5} I_{8} \rightarrow{ }^{5} I_{6}$ ground state absorption. On the other hand, it was established that the excited state absorption transition ${ }^{5} I_{6}$ $\rightarrow{ }^{5} S_{2}$ had a weak overlap with ground state absorption. Using numerical solution of the rate equations, we show that $\mathrm{Ho}^{3+}$-doped fluoride fiber lasers employing pumping at $1100 \mathrm{~nm}$ rely on excited state absorption from the lowest excited state of $\mathrm{Ho}^{3+}$ to maintain a population inversion and that energy transfer upconversion processes compete detrimentally with the excited state absorption processes in concentrated $\mathrm{Ho}^{3+}$-doped fluoride glass. () 2008 American Institute of Physics.

[DOI: $10.1063 / 1.2833436]$

\section{INTRODUCTION}

Fiber lasers have made a significant impact in industry and research because of their capability of providing near diffraction-limited laser output in a compact, efficient, and, thus, cost effective device. The geometry and size of the fiber waveguide means that they are comparatively less affected by thermal problems and a high spatial quality output beam can typically be produced at very high output power levels. ${ }^{1}$

Many applications such as laser surgery ${ }^{2-4}$ and remote sensing $^{5-7}$ are dependent on high power midinfrared radiation and, as a result, there exists a strong demand for the development of high power and efficient midinfrared laser devices. A midinfrared fiber laser that offers high power and high efficiency remains a technological challenge; however, a number of interesting and potentially power scalable midinfrared fiber laser alternatives, which operate at the short wavelength region of the midinfrared spectrum (at $\sim 3 \mu \mathrm{m}$ ) have been demonstrated. ${ }^{8-11}$

The fluoride glasses based on the composition $\mathrm{ZrF}_{4}-\mathrm{BaF}_{2}-\mathrm{LaF}_{3}-\mathrm{NaF}$ (ZBLAN), which have the necessarily low maximum phonon energy, are currently the most developed host materials for midinfrared fiber lasers. Of the rare earth doped fiber lasers that have been tested for the generation of $\sim 3 \mu \mathrm{m}$ radiation, fluoride fiber lasers based on the ${ }^{5} I_{11 / 2} \rightarrow{ }^{5} I_{13 / 2}$ laser transition of the $\mathrm{Er}^{3+}$ ion producing $\sim 2.7 \mu \mathrm{m}$ laser radiation have presented the highest output power. ${ }^{12}$ On the other hand, the emission wavelength (of between 2.84 and $2.86 \mu \mathrm{m}$ ) relevant to the ${ }^{5} I_{6} \rightarrow{ }^{5} I_{7}$ laser

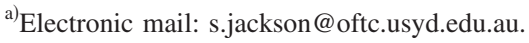

transition of $\mathrm{Ho}^{3+}$ overlaps well with the fundamental vibration of the $\mathrm{OH}$ bond, and the potentially improved power scalability of midinfrared $\mathrm{Ho}^{3+}$-based ZBLAN fiber lasers compared to $\mathrm{Er}^{3+}$-doped ZBLAN fiber lasers has instigated further research.

Past demonstrations of midinfrared $\mathrm{Ho}^{3+}$-doped ZBLAN fiber lasers have involved excitation with the use of either $\mathrm{Yb}^{3+}$-doped silica fiber lasers operating at $1.1 \mu \mathrm{m},{ }^{11,13}$ or Raman fiber lasers pumped operating at $1.15 \mu \mathrm{m} .{ }^{14}$ These versatile approaches to the excitation of midinfrared fiber lasers have allowed the demonstration of alternative midinfrared fiber lasers including the $\mathrm{Dy}^{3+}$-doped ZBLAN fiber laser. ${ }^{15}$ But, in a similar way to the $\mathrm{Er}^{3+}$ ion transition, the lifetime of the lower laser level of the $\mathrm{Ho}^{3+}$ ion is longer (12 ms) compared to the $3.5 \mathrm{~ms}$ lifetime of the upper laser level. As a result, the demonstration of $\sim 2.5 \mathrm{~W}$ from a $\mathrm{Ho}^{3+}$-doped ZBLAN fiber laser ${ }^{11}$ required $\mathrm{Pr}^{3+}$ ion desensitization in order to reduce population bottlenecking at the lower ${ }^{5} I_{7}$ laser level.

Recently, ${ }^{16}$ we identified and quantified a range of energy transfer upconversion (ETU) processes that involve the ${ }^{5} I_{6}$ and ${ }^{5} I_{7}$ energy levels of $\mathrm{Ho}^{3+}$ in singly $\mathrm{Ho}^{3+}$-doped ZBLAN glass. In contrast to demonstrations requiring desensitization, the production of $340 \mathrm{~mW}$ output power from a high concentration $(4.2 \mathrm{~mol} \%)$ singly $\mathrm{Ho}^{3+}$-doped ZBLAN fiber laser ${ }^{13}$ was thought to relate to one of these ETU processes that acts to reduce the electron population in the lower laser level and repopulate the upper laser level. In this investigation, we extend this work by identifying and quantifying a range of pump excited state absorption (ESA) processes that affect the functioning of $\mathrm{Ho}^{3+}$-doped ZBLAN fiber la- 
TABLE I. Luminescence branching ratio, and experimental and radiative lifetimes of $\mathrm{Ho}^{3+}$ used in the rate equations.

\begin{tabular}{|c|c|c|c|c|}
\hline \multicolumn{5}{|c|}{ Luminescence branching ratio and radiative lifetimes of $\mathrm{Ho}^{3+\mathrm{a}}$} \\
\hline Transition & $\beta$ & $\tau_{R}$ & $\begin{array}{c}\tau(\exp ) \\
\left(\left[\mathrm{Ho}^{3+}\right]=4 \mathrm{~mol} \%\right)^{\mathrm{b}}\end{array}$ & $\begin{array}{l}W_{\mathrm{nr}} \\
\left(\mathrm{s}^{-1}\right)\end{array}$ \\
\hline${ }^{5} S_{2} \rightarrow$ & & $340 \mu \mathrm{s}$ & $300 \mu \mathrm{s}$ & 392 \\
\hline${ }^{5} I_{6}$ & 0.06 & & $(21 \mu \mathrm{s})$ & \\
\hline${ }^{5} I_{7}(741 \mathrm{~nm})$ & 0.34 & & & \\
\hline${ }^{5} I_{8}(538 \mathrm{~nm})$ & 0.61 & & & \\
\hline${ }^{5} F_{5} \rightarrow$ & & $17 \mathrm{~ms}$ & $50 \mu \mathrm{s}$ & 19941 \\
\hline${ }^{5} I_{7}(1162 \mathrm{~nm})$ & 0.55 & & & \\
\hline${ }^{5} I_{8}(899 \mathrm{~nm})$ & 0.41 & & & \\
\hline${ }^{5} I_{6} \rightarrow$ & & $5.9 \mathrm{~ms}$ & $3.5 \mathrm{~ms}$ & 116.2 \\
\hline${ }^{5} I_{7}(2889 \mathrm{~nm})$ & 0.09 & & $(4.6 \mathrm{~ms})$ & \\
\hline${ }^{5} I_{8}(1168 \mathrm{~nm})$ & 0.91 & & & \\
\hline${ }^{5} I_{7} \rightarrow$ & & $12.6 \mathrm{~ms}$ & $12 \mathrm{~ms}$ & \\
\hline${ }^{5} I_{8}(1960 \mathrm{~nm})$ & 1 & & $(31.8 \mathrm{~ms})$ & \\
\hline \multicolumn{5}{|c|}{$\mathrm{Ho}^{3+}-\mathrm{Ho}^{3+}$ energy transfer rates constants ${ }^{\mathrm{c}}$} \\
\hline $\begin{array}{l}\mathrm{Ho}^{3+}(4 \mathrm{~mol} \%) \\
\text { Process }\end{array}$ & $\begin{array}{c}I\left(\text { ions } \mathrm{cm}^{-3}\right) \\
\text { (excitation density) }\end{array}$ & $K_{\mathrm{ETU}}\left(\mathrm{s}^{-1}\right)$ & $K_{0}\left(\mathrm{~s}^{-1}\right)$ & $W_{\mathrm{CR}}\left(\mathrm{s}^{-1}\right)$ \\
\hline ETU1 & $1.6 \times 10^{18} \mathrm{~cm}^{-3}$ & 70 & 72 & $\cdots$ \\
\hline ETU2 & $3.4 \times 10^{18} \mathrm{~cm}^{-3}$ & 623 & 650 & $\cdots$ \\
\hline CR1 & & $\cdots$ & & 19487 \\
\hline CR2 & & & & 43859 \\
\hline
\end{tabular}

sers operating on the midinfrared ${ }^{5} I_{6} \rightarrow{ }^{5} I_{7}$ laser transition. We show, using a numerical model, that correctly predicts the performance of $\mathrm{Ho}^{3+}$-doped ZBLAN fiber lasers pumped at $1.1 \mu \mathrm{m}$ that pump ESA processes are primarily responsible for the recycling of energy back to the upper laser level.

\section{EXPERIMENTAL PROCEDURE}

The $\mathrm{Ho}^{3+}$-doped ZBLAN glass samples used for the time-resolved luminescence spectroscopy measurements were prepared from ultrapure fluoride starting materials in the composition $(100-x) \quad\left(53 \mathrm{ZrF}_{4}-20 \mathrm{BaF}_{2}-4 \mathrm{LaF}_{3}-\right.$ $20 \mathrm{NaF})-x \mathrm{HoF}_{3}(x=4 \mathrm{~mol} \%)$. The starting powder materials were melted at $850{ }^{\circ} \mathrm{C}$ for $120 \mathrm{~min}$ in a Pt-Au crucible. The liquids were poured into brass molds and annealed at $260{ }^{\circ} \mathrm{C}$ for $2 \mathrm{~h}$ to remove the mechanical stresses. The samples were cut and polished into $15 \times 10 \times 5 \mathrm{~mm}^{3}$ pieces.

Absorption spectra in the range of $300-2000 \mathrm{~nm}$ were measured using a spectrophotometer (Cary/OLIS 17D). The decay characteristics of the excited states of $\mathrm{Ho}^{3+}$ were measured using pulsed (4 ns) laser excitation from a tunable optical parametric oscillator (OPO) pumped by the second harmonic of a $Q$-switched neodymium-doped yttrium aluminum garnet (Nd-YAG) laser (Brilliant B from Quantel). Tunable laser excitation from the OPO was used to excite the ${ }^{5} I_{6}$ and ${ }^{5} I_{7}$ energy levels directly. The luminescence was detected using an S-20 photomultiplier tube (EMI, refrigerated to $-20{ }^{\circ} \mathrm{C}$ ) using a shunt resistance of $50 \Omega$ (anode pulse rise time of $10 \mathrm{~ns}$ ) and analyzed using a digital $200 \mathrm{MHz}$ oscilloscope (Tektronix TDS 410). The luminescence signals in the visible to near infrared region were isolated using a $0.25 \mathrm{~m}$ monochromator (KRATOS) containing a dispersion grating with 1200 grooves $\mathrm{mm}^{-1}$. All the fluorescence decay characteristics were measured at $300 \mathrm{~K}$.

\section{EXPERIMENTAL RESULTS}

Time resolved luminescence spectroscopy using selective pulsed laser excitation in the wavelength range of $1110-1220 \mathrm{~nm}$ was used to investigate the upconversion processes involving the ${ }^{5} I_{6}$ and ${ }^{5} I_{7}$ levels. These upconversion processes relate to either pump ESA in which the ${ }^{5} I_{6}$ or ${ }^{5} I_{7}$ levels absorb pump photons or ETU via nonradiative energy transfer between the excited ${ }^{5} I_{6}$ or ${ }^{5} I_{7}$ levels. These ETU processes have been investigated in detail in a previous investigation ${ }^{16}$ and the experimental and the radiative lifetimes of the ${ }^{5} S_{2},{ }^{5} F_{5},{ }^{5} I_{5},{ }^{5} I_{6}$, and ${ }^{5} I_{7}$ levels of $\mathrm{Ho}^{3+}$ are shown in Table I. Included in Table I are the rates of the relevant ETU processes $\mathrm{Ho}^{3+}\left({ }^{5} I_{7},{ }^{5} I_{7}\right) \rightarrow \mathrm{Ho}^{3+}\left({ }^{5} I_{6},{ }^{5} I_{8}\right)$, labeled ETU1, and $\mathrm{Ho}^{3+}\left({ }^{5} I_{6},{ }^{5} I_{6}\right) \rightarrow \mathrm{Ho}^{3+}\left({ }^{5} F_{5},{ }^{5} I_{8}\right)$, labeled ETU2, and the cross relaxation process $\mathrm{Ho}^{3+}\left({ }^{5} F_{5},{ }^{5} I_{8}\right)$ $\rightarrow \mathrm{Ho}^{3+}\left({ }^{5} I_{6},{ }^{5} I_{7}\right)$ which is labeled CR1.

\section{A. Pump excited state absorption from the ${ }^{5} I_{6}$ level}

Figure 1 displays the emission response at a wavelength of $545 \mathrm{~nm}$ after short pulse laser excitation at $1151 \mathrm{~nm}$. This emission relates to the decay of the ${ }^{5} S_{2}$ level and it exhibits a fast rise time comparable with the $\sim 10$ ns response time of the detection system. The decay time of the ${ }^{5} S_{2}$ state in $\mathrm{Ho}^{3+}$ 


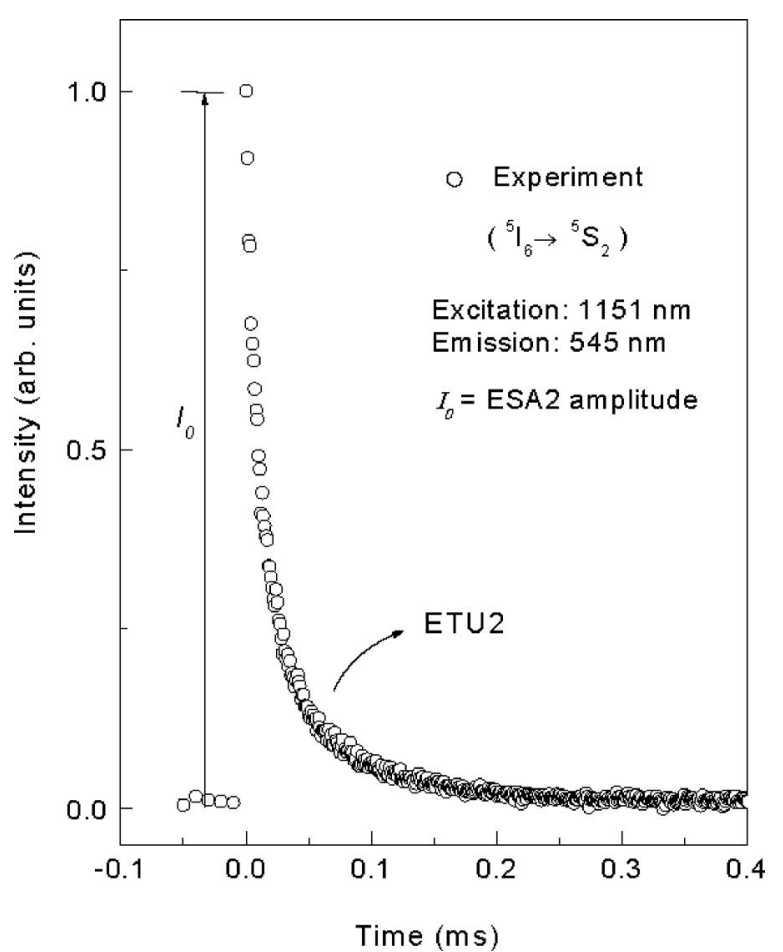

FIG. 1. Measured luminescence characteristic of the ${ }^{5} S_{2}$ excited state of $\mathrm{Ho}^{3+}$ measured at $545 \mathrm{~nm}$ after laser excitation with $4 \mathrm{~ns}, 10 \mathrm{~mJ}(10 \mathrm{~Hz})$ pulses at $1151 \mathrm{~nm}$.

$(0.1 \mathrm{~mol} \%)$-doped ZBLAN was $300 \mu$ s that decreased to $21 \mu \mathrm{s}$ in $\mathrm{Ho}^{3+}(4 \mathrm{~mol} \%)$-doped ZBLAN due to the $\mathrm{Ho}^{3+}\left({ }^{5} S_{2},{ }^{5} I_{8}\right) \rightarrow \mathrm{Ho}^{3+}\left({ }^{5} I_{4},{ }^{5} I_{7}\right)$ nonradiative cross relaxation decay process, which we label CR2, as verified by exciting it directly with photons at a wavelength of $532 \mathrm{~nm} .{ }^{16}$ We interpret the green emission as being produced by pump photon absorption by way of the ESA process ${ }^{5} I_{6} \rightarrow{ }^{5} S_{2}$, which we label ESA2. Assigning the emission intensity just after the pump pulse (at $t \sim 0$ ) the initial amplitude of the green emission, $I_{0}$, we can plot the values for $I_{0}$ as a function of pump wavelength, as shown in Fig. 2(a). The two-photon absorption process is represented by (i) ${ }^{5} I_{8}+h \nu_{P} \rightarrow{ }^{5} I_{6}$ and (ii) ${ }^{5} I_{6}$ $+h \nu_{P} \rightarrow{ }^{5} S_{2}$; the absorption of the second pump photon is nonresonant.

The solid line in Fig. 2(a) was obtained using a leastsquares fit to the experimental data with three Gaussian functions: the peak positions of the functions occurring at 1126, 1144, and $1158 \mathrm{~nm}$. We chose to use Gaussian functions for the decomposition of the $545 \mathrm{~nm}$ excitation spectrum because these functions have been used to describe the absorption and emission transitions between electronic levels of ions in solids that have a random distribution of the local electric fields at the ion sites. ${ }^{17}$ The ground state absorption (GSA) spectrum is shown in Fig. 2(b). It can be observed that the two-photon absorption process, which leads to the emission of $545 \mathrm{~nm}$ luminescence, does not follow the GSA spectrum; the main peak in the GSA spectrum occurs at a wavelength of $1151 \mathrm{~nm}$.

\section{B. Pump excited state absorption from the ${ }^{5} / 7$ level}

Evidence that the ${ }^{5} I_{4}$ and ${ }^{5} I_{5}$ energy levels of $\mathrm{Ho}^{3+}$ are excited after laser excitation of a $\mathrm{Ho}^{3+}(4.2 \mathrm{~mol} \%)$-doped
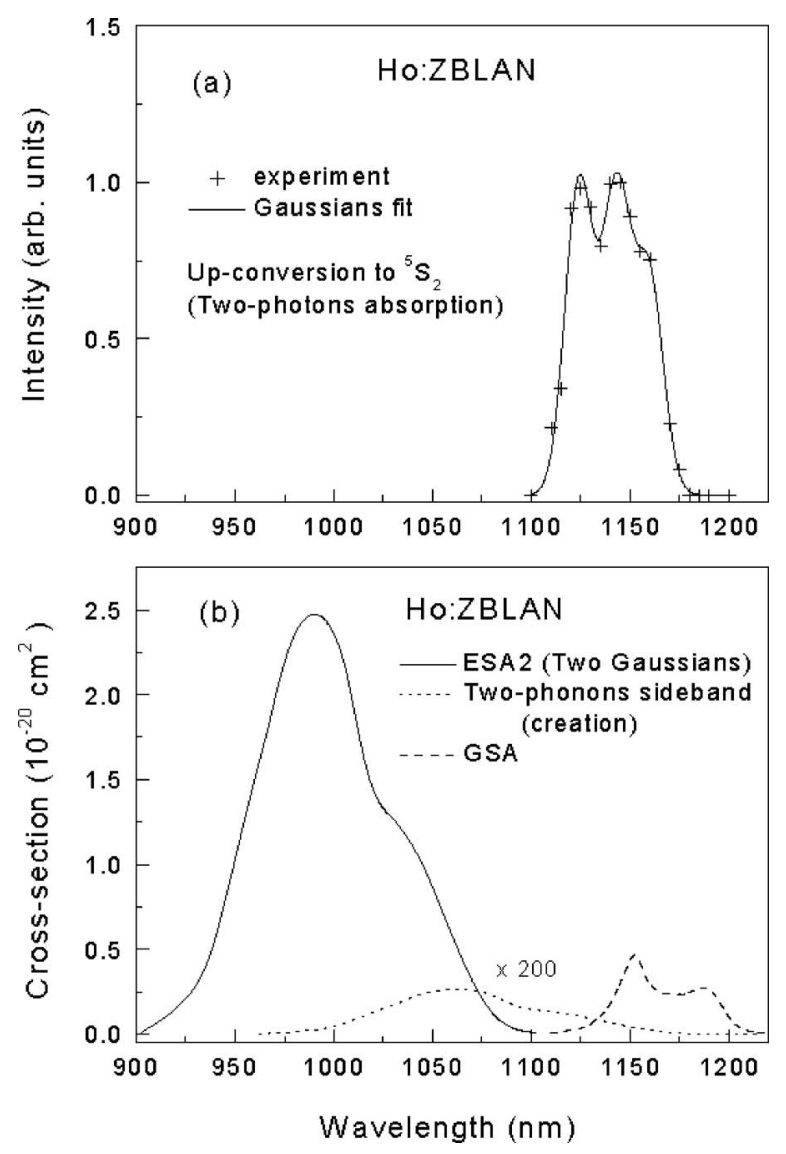

FIG. 2. (a) Measurements of the excitation spectrum for emission at $545 \mathrm{~nm}$ from the ${ }^{5} S_{2}$ level after pulsed laser excitation that was tuned to the ${ }^{5} I_{8}$ $\rightarrow{ }^{5} I_{6}$ GSA transition. Crosses are the experimental data and the solid line is a least-squares fit using three Gaussian functions. (b) The solid line represents the calculated cross section of the ESA2 process using two superimposed Gaussian functions which were scaled by the radiative rate of the ${ }^{5} S_{2}$ level $\left(\tau_{R}=300 \mu \mathrm{s}\right)$. The dotted line represents the calculated two-phonon absorption sideband and the dashed line is the measured GSA.

ZBLAN fiber laser at wavelengths near $1100 \mathrm{~nm}$ was shown in the visible spectrum emitted from the fiber. ${ }^{13}$ In the present investigation, we could observe the upconverted luminescence at $899 \mathrm{~nm}$ which results from fluorescence from the ${ }^{5} I_{5}$ level when exciting the ${ }^{5} I_{8} \rightarrow{ }^{5} I_{6}$ GSA transition with our short pulse probe light. Figure 3(a) shows the weak $899 \mathrm{~nm}$ emission response induced by the probe pulses at $1180 \mathrm{~nm}$. As can be observed in Fig. 3(b), the luminescence comprises of two separate rise times; the first with a rise time of $\sim 1 \mu$ s due to ${ }^{5} I_{4}$ excited level decay which is comparatively fast because the ${ }^{5} I_{4}$ level decays nonradiatively by way of multiphonon emission and a second slower rise time of $\sim 50 \mu$ s that is well-matched with the expected lifetime of the ${ }^{5} I_{5}$ level at room temperature. ${ }^{18}$ The overall process can be represented by (i) ${ }^{5} I_{8}+h \nu_{P} \rightarrow{ }^{5} I_{6}$; (ii) ${ }^{5} I_{6} \rightarrow{ }^{5} I_{7}+h \nu$ $(2.9 \mu \mathrm{m})$; (iii) ${ }^{5} I_{7}+h \nu_{P} \rightarrow{ }^{5} I_{4} \rightarrow{ }^{5} I_{5}+\hbar \omega$ (phonons). The long decay time of the $899 \mathrm{~nm}$ emission observed in Fig. 3(a) is consistent with the mean decay time of $\sim 6.83 \mathrm{~ms}$ measured for the ${ }^{5} F_{5}$ level ${ }^{16}$ in $\mathrm{Ho}^{3+}(4 \mathrm{~mol} \%)$-doped ZBLAN glass which is excited by the ETU2 process after the ${ }^{5} I_{6}$ level is populated by GSA: the ${ }^{5} I_{5}$ level is populated after multiphonon decay from the ${ }^{5} F_{5}$ level through the ${ }^{5} I_{4}$ level.

The initial amplitude $I_{0}$ of the $899 \mathrm{~nm}$ emission was measured $\sim 2 \mu$ s after the probe pulse in order to isolate the 

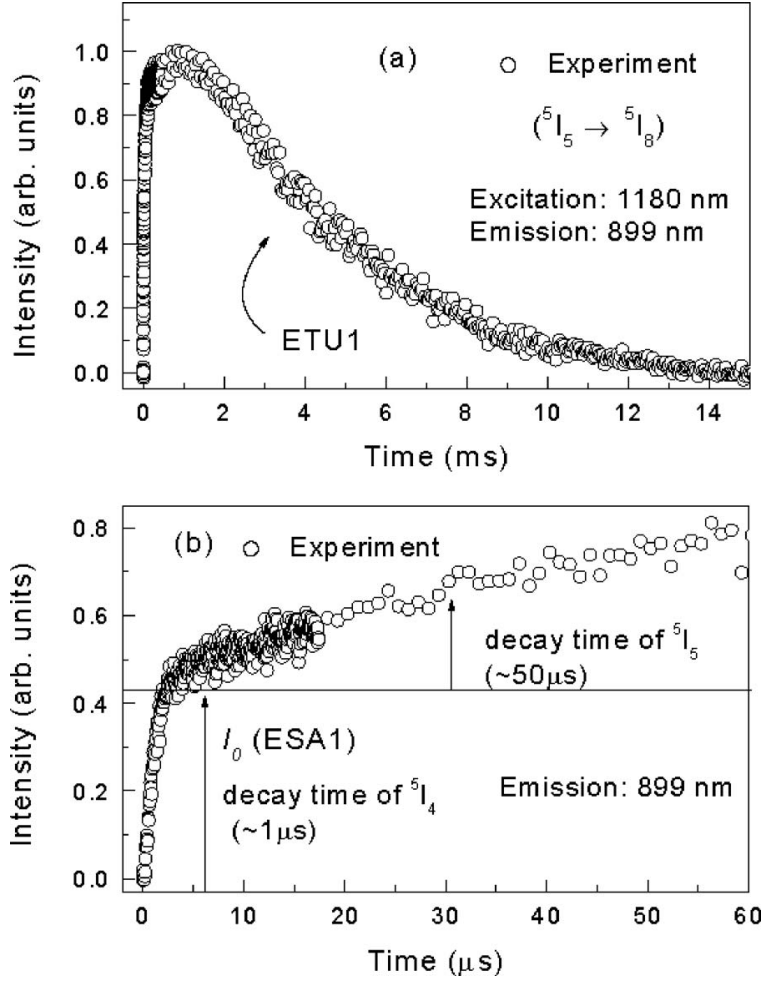

FIG. 3. Measured (a) luminescence characteristic at $899 \mathrm{~nm}$ from the ${ }^{5} I_{5}$ level after laser excitation with $4 \mathrm{~ns}, 10 \mathrm{~mJ}(10 \mathrm{~Hz})$ pulses at $1180 \mathrm{~nm}$. The long decay time (of $\sim 7 \mathrm{~ms}$ ) is due to the long decay of the ${ }^{5} F_{5}$ excited state that is populated by ETU1 and (b) detail of the temporal characteristic of the $899 \mathrm{~nm}$ emission in the $0-60 \mu$ s range.

contribution from ESA for a range of probe wavelengths tuned over the ${ }^{5} I_{8} \rightarrow{ }^{5} I_{6}$ GSA transition of $\mathrm{Ho}^{3+}$. Figure 4(a) shows the values (crosses) of $I_{0}$ as a function of the probe wavelength and the solid line in Fig. 4(a) represents the best fit to the experimental data using a least-squares fit comprising three Gaussian functions which are centered at 1145, 1175 , and $1215 \mathrm{~nm}$. It can be observed that the two-photon excitation band follows approximately with the GSA spectrum shown in Fig. 4(b). By inspection of the minimum and maximum energies of ${ }^{5} I_{7} \rightarrow{ }^{5} I_{4}$ transition of $\mathrm{Ho}^{3+}$ in ZBLAN, it can be deduced that the ESA1 spectrum will occur in the range covered by the two-photon excitation spectrum. One may obtain the ESA1 spectrum [or $S(\lambda)$ ] by means of the normalized two-photon absorption (TPA) and GSA spectra using the following relation:

$$
S(\lambda)=\frac{\operatorname{TPA}(\lambda)}{\operatorname{GSA}(\lambda)} .
$$

The solid line in Fig. 4(c) shows the cross section of the ESA1 process using Eq. (1).

\section{Calculation of the ESA cross sections}

Using the Judd-Ofelt theory it is possible to estimate the ESA1 cross section. The rate of spontaneous emission from ${ }^{5} I_{J}$ state for an electric dipole transition is given by ${ }^{19}$

$$
A^{\text {ed }}\left(J, J^{\prime}\right)=\frac{64 \pi^{4} e^{2} \chi}{3 h \lambda^{3}} S^{\text {ed }},
$$
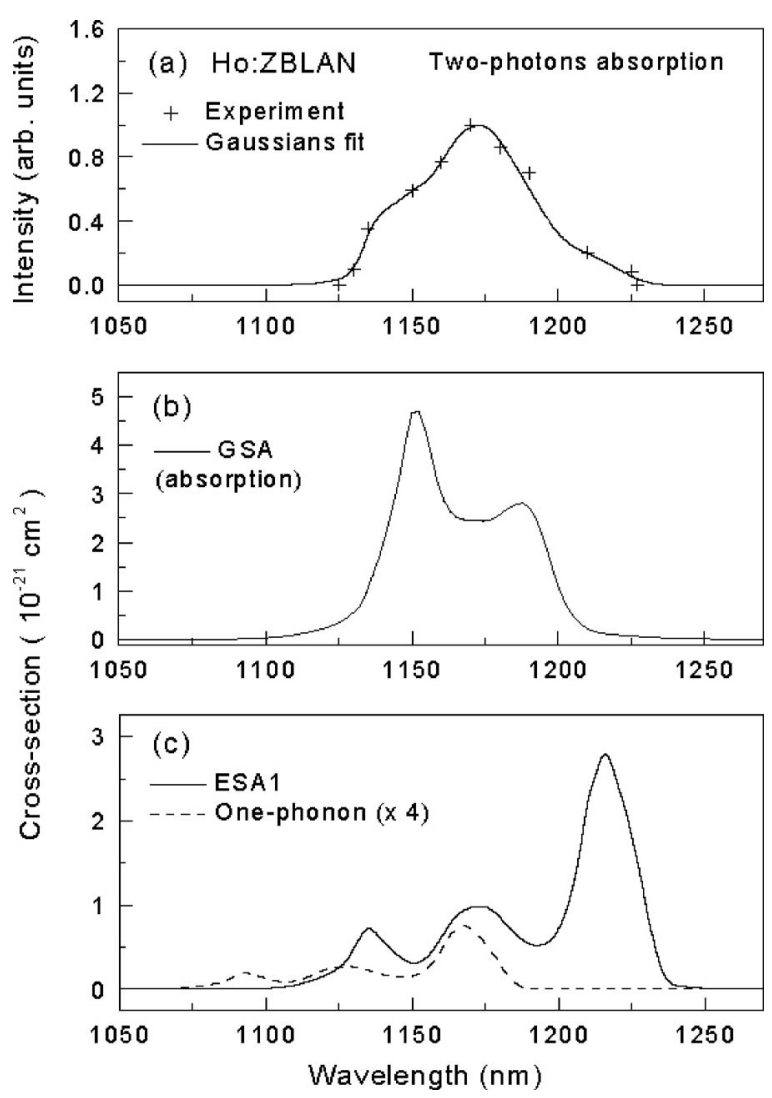

FIG. 4. Measured (a) excitation spectrum (crosses) of the $899 \mathrm{~nm}$ emission intensity $I_{0}$ measured $2 \mu \mathrm{s}$ after the probe pulses which were tuned from 1110 to $1220 \mathrm{~nm}$ and (b) cross section of the GSA spectrum of the ${ }^{5} I_{8}$ $\rightarrow{ }^{5} I_{6}$ transition. (c) Calculated cross section for the ESA1 transition (solid line) and the calculated one-phonon sideband (dotted line).

where $\quad S^{\text {ed }}=[1 /(2 J+1)] \Sigma_{\lambda=2,4,6} \Omega_{\lambda}\left|\left\langle U^{(\lambda)}\right\rangle\right|^{2} \quad$ and $\quad \chi=n\left(n^{2}\right.$ $+2)^{2} / 9$. The spectroscopic intensity parameters $\Omega_{2}, \Omega_{4}$, and $\Omega_{6}$ are equal to $230 \times 10^{-22}, 230 \times 10^{-22}$, and 171 $\times 10^{-22} \mathrm{~cm}^{2}$, respectively, for $\mathrm{Ho}^{3+}$-doped ZBLAN. ${ }^{20}$ Values of $\left|\left\langle U^{(\lambda)}\right\rangle\right|^{2}$ were obtained from the literature ${ }^{19}$ for all the radiative transitions from the ${ }^{5} I_{4}$ excited state of $\mathrm{Ho}^{3+}$ are listed in Table II. The refractive index $n=1.45$ for ZBLAN. The absorption cross section spectrum due to ${ }^{5} I_{7} \rightarrow{ }^{5} I_{4}$ transition (or ESA1 band) was calculated using Eq. (2) and $\bar{\lambda}$

TABLE II. Values of the matrix elements of the unit angular tensor operator $\left|\left\langle U^{(\lambda)}\right\rangle\right|^{2}$. [These values were obtained from the literature (Ref. 19) for the radiative transitions from ${ }^{5} I_{4}$ excited state of $\mathrm{Ho}^{3+}$. The calculated radiative lifetime of ${ }^{5} I_{4}$ state in $\mathrm{Ho}^{3+}$-doped ZBLAN was $14.3 \mathrm{~ms}$. The measured one was $1 \mu \mathrm{s}$ and the luminescence efficiency was observed to be equal to 7 $\times 10^{-5}$.]

\begin{tabular}{lcccc}
\hline \hline \multicolumn{1}{c}{$\begin{array}{c}\text { Transition } \\
\bar{\lambda}(\mathrm{nm})\end{array}$} & $\left|\left\langle U^{(2)}\right\rangle\right|^{2}$ & $\left|\left\langle U^{(4)}\right\rangle\right|^{2}$ & $\left|\left\langle U^{(6)}\right\rangle\right|^{2}$ & $A^{\text {ed }}\left(\mathrm{s}^{-1}\right)$ \\
\hline${ }^{5} I_{4} \rightarrow{ }^{5} I_{5}$ & 0.0312 & 0.1237 & 0.9099 & 0.33 \\
$(4472)$ & 0.0022 & 0.0281 & 0.6640 & 29.7 \\
$\begin{array}{l}{ }^{5} I_{4} \rightarrow{ }^{5} I_{6} \\
(2064)\end{array}$ & 0.0000 & 0.0033 & 0.1568 & 33.2 \\
${ }^{5} I_{4} \rightarrow{ }^{5} I_{7}$ & 0.0000 & 0.0000 & 0.0077 & 6.8 \\
$(1211)$ & & & & \\
${ }^{5} I_{4} \rightarrow{ }^{5} I_{8}$ & & & & \\
$(749)$ & & & & \\
\hline
\end{tabular}


$=1211 \mathrm{~nm}$ (average excitation wavelength or centroid) $\int S(\lambda) d \lambda=43.5 \mathrm{~nm}$ (integrated line shape), and $\Sigma_{J^{\prime}} A_{J^{\prime}}^{\text {ed }}$ $=70.4 \mathrm{~s}^{-1}$ [the total radiative decay rate of the ${ }^{5} I_{4}$ excited state calculated using Eq. (2)]. The absorption cross section is given by

$$
\sigma_{i \rightarrow f}^{\mathrm{abs}}(\lambda)=\frac{\overline{\lambda^{4}}}{8 \pi c} \frac{g_{f}}{g_{i}}\left(\sum_{J^{\prime}} A_{J^{\prime}}^{\mathrm{ed}}\right) \frac{S(\lambda)}{\int S(\lambda) d \lambda},
$$

where $g=2 J+1$ ( $i$ for the initial and $f$ for the final states), $S(\lambda)$ is the line shape of the ESA spectrum, and $c$ the speed of light. The maximum cross section for ESA1 is equal to $2.35 \times 10^{-21} \mathrm{~cm}^{2}$ at $\lambda=1216 \mathrm{~nm}$, which corresponds to approximately $1 / 2$ of the maximum cross section for GSA, which is $4.7 \times 10^{-21} \mathrm{~cm}^{2}$ at $\lambda=1149 \mathrm{~nm}$. The resultant ESA1 band was calculated using Eq. (1) providing the spectrum shown in Fig. 4(c). The ground state absorption (GSA) is shown in Fig. 4(b) for comparison with the ESA1 band.

The crucial result from this work is that the ESA processes, ESA1 and ESA2, directly excite ${ }^{5} I_{4}$ and ${ }^{5} S_{2}$ levels, respectively, when $\mathrm{Ho}^{3+}$-doped ZBLAN glass is pumped on the GSA process ${ }^{5} I_{8} \rightarrow{ }^{5} I_{6}$. The $1100 \mathrm{~nm}$ pump wavelength, ${ }^{13}$ however, is outside the excitation spectrum arising from TPA, as shown Figs. 2(a) and 4(a). Thus, the visible emission that was observed in Ref. 13 suggests that the ESA1 and ESA2 processes must have been assisted by the phonons of the glass. For a complete description, the ESA cross sections and ESA spectral line shapes including the phonon sidebands must be taken into account to determine the contribution of the ESA processes to the $3 \mu \mathrm{m}$ fiber laser.

The dashed line in Fig. 4(c) shows the one-phonon sideband of ESA1, i.e., the ESA transition assisted by onephonon annihilation. The sideband spectrum was calculated using the method employed in Ref. 21, which is based on the fact that the phonon sideband results from an optical transition coupled to the local phonon field, whereby phonons are created to produce a high energy sideband or they are annihilated to produce a low energy sideband. In the case of excitation at $1100 \mathrm{~nm}$, the ESA1 process is completed when one or two phonons are absorbed from the glass. In this case, the sideband is obtained by means of $\operatorname{ESA} 1(\lambda)$ spectrum by shifting the wavelength $\lambda$ to $\lambda_{k}^{-}$according to the relation $\lambda_{k}^{-}=(1 / \lambda-k \hbar \omega)^{-1}$, where $k \hbar \omega$ is the total (phonon) energy absorbed from the lattice. The sideband amplitude must be scaled using the $k$-phonon annihilation probability $P_{k}^{-}$ that is given by $P_{k}^{-} \cong \exp \left(-2 \bar{n} S_{0}\right)\left(S_{0}^{k} / k !\right)(\bar{n})^{k}$, where $\bar{n}$ $=[\exp (\hbar \omega / K T)-1]^{-1}$ is the occupation number of the phonon mode (at $T=300 \mathrm{~K}$ ). $S_{0} \sim 0.31$ is the electron-phonon coupling (or Huang-Rhys factor) and $\hbar \omega=330 \mathrm{~cm}^{-1}$ is the average phonon energy of all the phonon modes which are coupled to the multiphonon sideband absorption relevant to ZBLAN glass. ${ }^{22}$ The one-phonon sideband was obtained according to the following relation: $S B\left(\lambda_{1}^{-}\right)=P_{1}^{-} \operatorname{ESA} 1\left(\lambda \rightarrow \lambda_{1}^{-}\right)$, where $P_{1}^{-}=0.068$. Figure $4(\mathrm{c})$ shows the high energy sideband spectrum and it indicates that one $(k=1)$ phonon annihilation is necessary to activate the ESA1 process when the pump wavelength is $1100 \mathrm{~nm}$.

The same approach was employed for the determination of the ESA2 sideband spectrum. Using the energy level dia- gram of $\mathrm{Ho}^{3+}$ in ZBLAN glass, ${ }^{20}$ one expects two primary absorption transitions comprising the ${ }^{5} I_{6} \rightarrow{ }^{5} S_{2}$ absorption when one considers the Stark sublevel structure of these energy levels in $\mathrm{Ho}^{3+}$-doped ZBLAN glass: the first transition with a peak p1 at $997 \mathrm{~nm}$ with a half-width $(H)$ of $54 \mathrm{~nm}$ and a second transition with a peak p2 at $1030 \mathrm{~nm}$ with $H$ $=34 \mathrm{~nm}$. The absorption spectrum of ESA2 was calculated using two superposed Gaussian functions and the Boltzmann distribution applied to the two distinguishable Stark levels of the $I_{6}$ level (at $T=300 \mathrm{~K}$ ) to scale the contribution of each transition to the total ESA2 absorption spectrum. Integration of the ESA2 spectrum gave $\int S(\lambda) d \lambda=64 \mathrm{~nm}$ and $\bar{\lambda}$ $=1010 \mathrm{~nm}$. Using the total radiative rate of the ${ }^{5} S_{2}$ level, $\Sigma_{J^{\prime}} A_{J^{\prime}}^{\text {ed }}=3334 \mathrm{~s}^{-1}$ (Ref. 20) in Eq. (3), we obtained the absorption cross section spectrum of ESA2, see solid line in Fig. 2(b). By inspecting this spectrum, one can conclude that a phonon sideband that involves one- or two-phonon emission accounts for the ESA that would take place under laser excitation at $1100 \mathrm{~nm}$. The two-phonon sideband was obtained by translating the ESA2 $(\lambda)$ spectrum using the relation $\lambda_{k}^{+}=[1 / \lambda+k \hbar \omega]^{-1} \quad($ where $k=2)$. The amplitude was scaled using the two-phonon emission probability given by $P_{k}^{+} \cong \exp \left[-(2 \bar{n}+1) S_{0}\right]\left(S_{0}^{k} / k !\right)(\bar{n}+1)^{k}$, where $k=2$ and, hence, $P_{2}^{+}=0.048$. The two-phonon sideband was calculated using the relation $S B\left(\lambda_{2}^{+}\right)=P_{2}^{+} \operatorname{ESA} 2\left(\lambda \rightarrow \lambda_{2}^{+}\right)$, whose spectrum is shown by the dotted line in Fig. 2(b). Comparing the results in Figs. 2(b) and 4(c), one can state that in order to produce ESA from the ${ }^{5} I_{6}$ level with a pump wavelength of $1100 \mathrm{~nm}$, the emission of two phonons is necessary and the estimated ESA cross section is $\sim 2.72 \times 10^{-23} \mathrm{~cm}^{2}$. On the other hand, the absorption of one phonon is necessary for ESA to take place from the ${ }^{5} I_{7}$ level and the ESA cross section is $\sim 4.7$ $\times 10^{-23} \mathrm{~cm}^{2}$.

\section{DISCUSSION}

Recently, ${ }^{23}$ it has been suggested that ESA, specifically ESA1 in the current investigation, was crucial to the operation of a $\mathrm{Ho}^{3+}$-doped ZBLAN fiber laser operating on the ${ }^{5} I_{6} \rightarrow{ }^{5} I_{7}$ transition. The authors reported a high slope efficiency of $45 \%$, despite the Stokes efficiency limit of $40 \%$, when the fiber was excited at $1175 \mathrm{~nm}$. The low $\left[\mathrm{Ho}^{3+}\right]$ of $0.5 \mathrm{~mol} \%$ in this fiber precluded strong rates of ETU and, therefore, ESA may have provided the energy recycling required to produce the pump-limited output power of $650 \mathrm{~mW}$. These results must be compared to the earlier demonstration of an output power of $340 \mathrm{~mW}$ at $2.92 \mu \mathrm{m}$ from a $\mathrm{Ho}^{3+}(4.2 \mathrm{~mol} \%)$-doped ZBLAN fiber laser that produced $5 \%$ slope efficiency when excited at $1100 \mathrm{~nm}$. Thus, a numerical simulation of these fiber lasers is necessary to elucidate the underlying mechanisms underpinning the performance of these $\mathrm{Ho}^{3+}$-doped ZBLAN fiber laser systems.

\section{A. Rate equations for optical excitation of the ${ }^{5} / 6$ level}

Figure 5 shows the simplified energy level scheme used to describe the $\mathrm{Ho}^{3+}$-doped ZBLAN laser system for $\mathrm{cw}$ laser pumping the $n_{3}$ level $\left({ }^{5} I_{6}\right) . n_{1}, n_{2}, n_{3}, n_{4}$, and $n_{5}$ are the ${ }^{5} I_{8}$, 


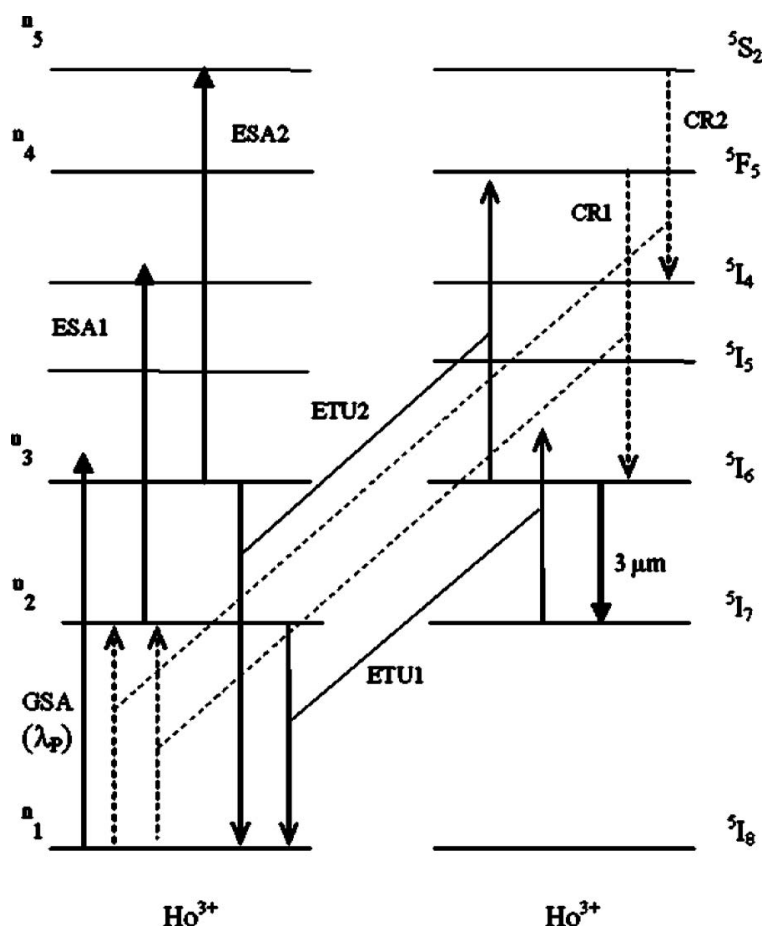

FIG. 5. Simplified energy level diagram for the $\mathrm{Ho}^{3+}$ ion showing the ground state absorption (GSA), excited state absorption (ESA), energy transfer upconversion (ETU), and cross relaxation (CR) processes.

${ }^{5} I_{7},{ }^{5} I_{6},{ }^{5} F_{5}$, and ${ }^{5} S_{2}$ populations of $\mathrm{Ho}^{3+}$, respectively, and $n_{1}+n_{2}+n_{3}+n_{4}+n_{5}=1$. The rate equations for the system are

$$
\begin{aligned}
\frac{d n_{1}}{d t}= & -R_{P} n_{1}+\frac{n_{2}}{\tau_{2}}+\frac{B_{31}}{\tau_{R_{3}}} n_{3}-W_{\mathrm{CR} 1} n_{1} n_{4}+K_{\mathrm{ETU} 2} n_{3}^{2} \\
& +\frac{\beta_{41}}{\tau_{R_{4}}} n_{4}+K_{\mathrm{ETU} 1} n_{2}^{2}+\frac{\beta_{51}}{\tau_{R 5}} n_{5}-W_{\mathrm{CR} 2} n_{1} n_{5},
\end{aligned}
$$

$$
\begin{aligned}
\frac{d n_{2}}{d t}= & W_{\mathrm{CR} 1} n_{1} n_{4}+\left(\frac{B_{32}}{\tau_{R_{3}}}+W_{\mathrm{nR}}(32)\right) n_{3}-\frac{n_{2}}{\tau_{2}}+\frac{\beta_{42}}{\tau_{R_{4}}} n_{4} \\
& -2 K_{\mathrm{ETU} 1} n_{2}^{2}+\frac{\beta_{52}}{\tau_{R 5}} n_{5}-K_{\mathrm{ESA} 1} n_{2}+W_{\mathrm{CR} 2} n_{1} n_{5},
\end{aligned}
$$

$$
\begin{aligned}
\frac{d n_{3}}{d t}= & R_{P} n_{1}+W_{\mathrm{CR} 1} n_{1} n_{4}-\frac{n_{3}}{\tau_{3}}-2 K_{\mathrm{ETU} 2} n_{3}^{2} \\
& +\left(\frac{\beta_{43}}{\tau_{R_{4}}}+W_{\mathrm{nR}}(43)\right) n_{4}+K_{\mathrm{ESA} 1} n_{2}-K_{\mathrm{ESA} 2} n_{3} \\
& +W_{\mathrm{CR} 2} n_{1} n_{5},
\end{aligned}
$$

$$
\begin{aligned}
& \frac{d n_{4}}{d t}=K_{\mathrm{ETU} 2} n_{3}^{2}-W_{\mathrm{CR} 1} n_{1} n_{4}-\frac{n_{4}}{\tau_{4}}+W_{\mathrm{nR}}(54) n_{5}, \\
& \frac{d n_{5}}{d t}=K_{\mathrm{ESA} 2} n_{3}-W_{\mathrm{CR} 2} n_{1} n_{5}-\frac{n_{5}}{\tau_{5}},
\end{aligned}
$$

where $R_{P}=\sigma_{13}\left(I_{P} / h \nu_{P}\right)$ is the pump rate $\left(\mathrm{s}^{-1}\right), I_{P}$ is the intensity of the pump light in $\mathrm{W} \mathrm{cm}-2$ and $h \nu_{P}$ is the photon energy of the pump radiation. $\beta_{i j}$ represents the luminescence branching ratio and $\tau_{R_{i}}$ is the radiative lifetime of the

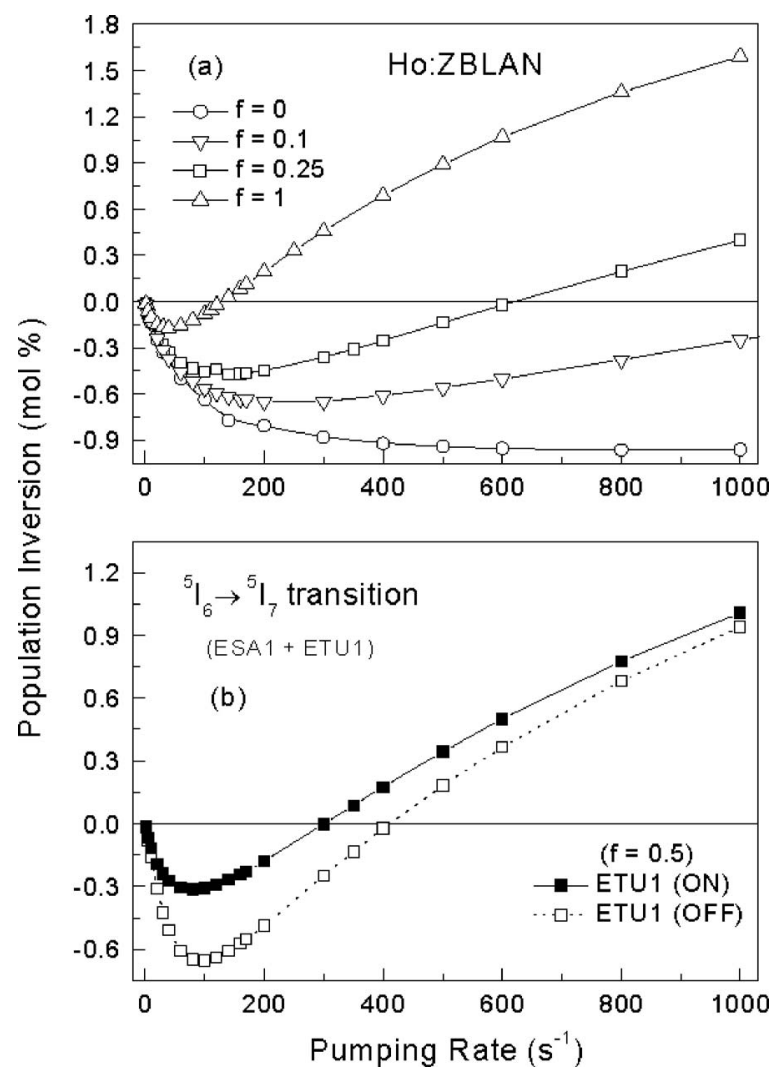

FIG. 6. Calculated steady state population inversion $\left(n_{3}-n_{2}\right)$ as a function of the pump rate and as a function of (a) $f$, the cross section ratio, and (b) of the contribution from ETU1 where $f=0.5$.

${ }^{5} S_{2},{ }^{5} F_{5},{ }^{5} I_{6}$, and ${ }^{5} I_{7}$ excited states where $i=5,4,3$, and 2 , respectively. The ESA1 pump ratio is given by $K_{\mathrm{ESA} 1}$ $=f R_{P}, f$, the cross section ratio, is given by $f$ $=\sigma_{\mathrm{ESAl}}\left(\lambda_{P}\right) / \sigma_{\mathrm{GSA}}\left(\lambda_{P}\right)$ and $\lambda_{P}$ is the pumping wavelength.

\section{B. Numerical solution of the rate equations}

It was established by numerical solution of Eqs. (4)-(8) that the ESA2 process does not contribute to the population inversion but depletes it slightly by approximately $5 \%$. As a result of this small contribution, ESA2 process was neglected in the rate equation model for laser pumping near $1100 \mathrm{~nm}$ and a saving in the computation time was achieved.

In order to better understand the role of ESA and ETU processes in the operation of singly $\mathrm{Ho}^{3+}$-doped ZBLAN fiber laser systems, we applied the numerical simulation to two $\mathrm{Ho}^{3+}$-doped ZBLAN systems: case 1, fiber laser employing fiber having $4.2 \mathrm{~mol} \% \mathrm{Ho}^{3+}$ pumped at $1100 \mathrm{~nm}$ corresponding to the experiment reported in Ref. 13, and, case 2, fiber laser employing fiber having $0.5 \mathrm{~mol} \% \mathrm{Ho}^{3+}$ pumped at $1175 \mathrm{~nm}$ which corresponds to the experiment reported in Ref. 23. In the case of the dilute $\mathrm{Ho}^{3+}$-doped ZBLAN system, i.e., case 2, the ETU processes were neglected in the rate equation system because it was established that these processes are important for $\mathrm{Ho}^{3+}$ concentrations above $1 \mathrm{~mol} \%$.

The results of the numerical simulations of the population inversion $\left(n_{3}-n_{2}\right)$ between the ${ }^{5} I_{6}$ and ${ }^{5} I_{7}$ levels for case 1, shown in Fig. 6(a), indicates that the ESA1 pump ratio makes a significant contribution to the system when $f$ 


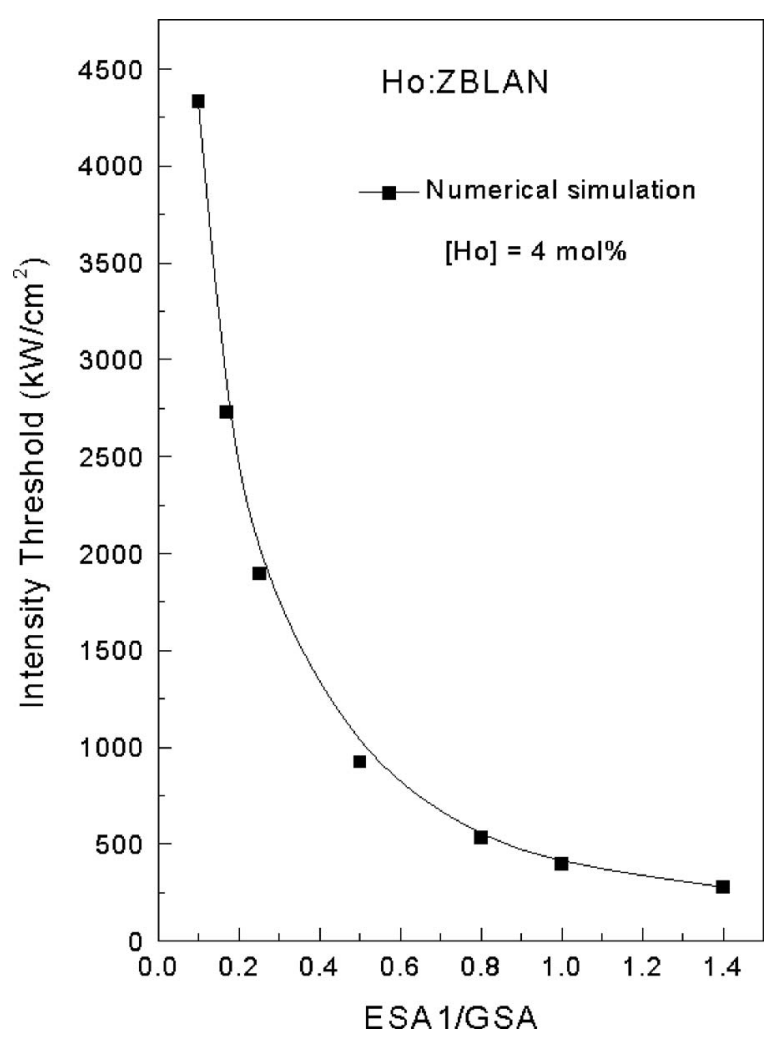

FIG. 7. Calculated pump intensity at the threshold for $2.92 \mu \mathrm{m}$ laser emission for $\mathrm{Ho}^{3+}(4 \mathrm{~mol} \%)$-doped ZBLAN as a function of the cross section ratio $f$.

$=K_{\mathrm{ESA} 1} / R_{P} \geqslant 0.1$, when the processes ETU1, ETU2, ESA1, and $\mathrm{CR} 1$ are considered. From these results, we can take the pump rate (or pump intensity) required to produce a zero population inversion for each $f$ value. Figure 7 shows the calculated pump intensity as a function of the $f$ parameter for $\mathrm{Ho}^{3+}(4 \mathrm{~mol} \%)$-doped ZBLAN pumped near $1100 \mathrm{~nm}$.

To determine the importance of ESA1 to the operation of the $\mathrm{cw} \mathrm{Ho}{ }^{3+}$-doped ZBLAN fiber laser, case 1, we calculated the pump ratio $f$ as a function of the pump wavelength; the results of which are shown in Fig. 8(a). The one-phonon sideband relevant to the ${ }^{5} I_{7} \rightarrow{ }^{5} I_{4}$ absorption transition, which increases the $f$ parameter from $\sim 0$ to $\sim 1.4$, is important in allowing ESA1 to contribute to the population inversion for excitation near $1100 \mathrm{~nm}$. In contrast, no sideband contribution to ESA1 is necessary for excitation near $1225 \mathrm{~nm}(f \sim 23)$. The predicted threshold intensity for excitation at $1100 \mathrm{~nm}$ was obtained by inspecting the threshold intensity behavior as a function of $f$ near $f \sim 1.4$, as shown in Fig. 7. A threshold intensity of $278 \mathrm{~kW} \mathrm{~cm}^{-2}$ was determined which is approximately $14 \%$ smaller than the experimental threshold intensity of $\sim 323 \mathrm{~kW} \mathrm{~cm}^{-2}$. $^{13}$ The numerical simulation of the population inversion presented in Fig. 8(b) shows that $2.9 \mu \mathrm{m}$ fiber laser operation using $\mathrm{Ho}^{3+}$ (4 mol \%)-doped ZBLAN will be more efficient with a pump wavelength near $1225 \mathrm{~nm}$ compared to $1100 \mathrm{~nm}$.

We analyzed the contribution of ETU1 to the population inversion for the case 1 fiber laser for two distinct cases when $f=0.5$ : (i) when ETU1 process is on and (ii) when ETU1 process is suppressed (off). Figure 6(b) shows that the pump intensity at threshold increases 1.4 times when ETU1
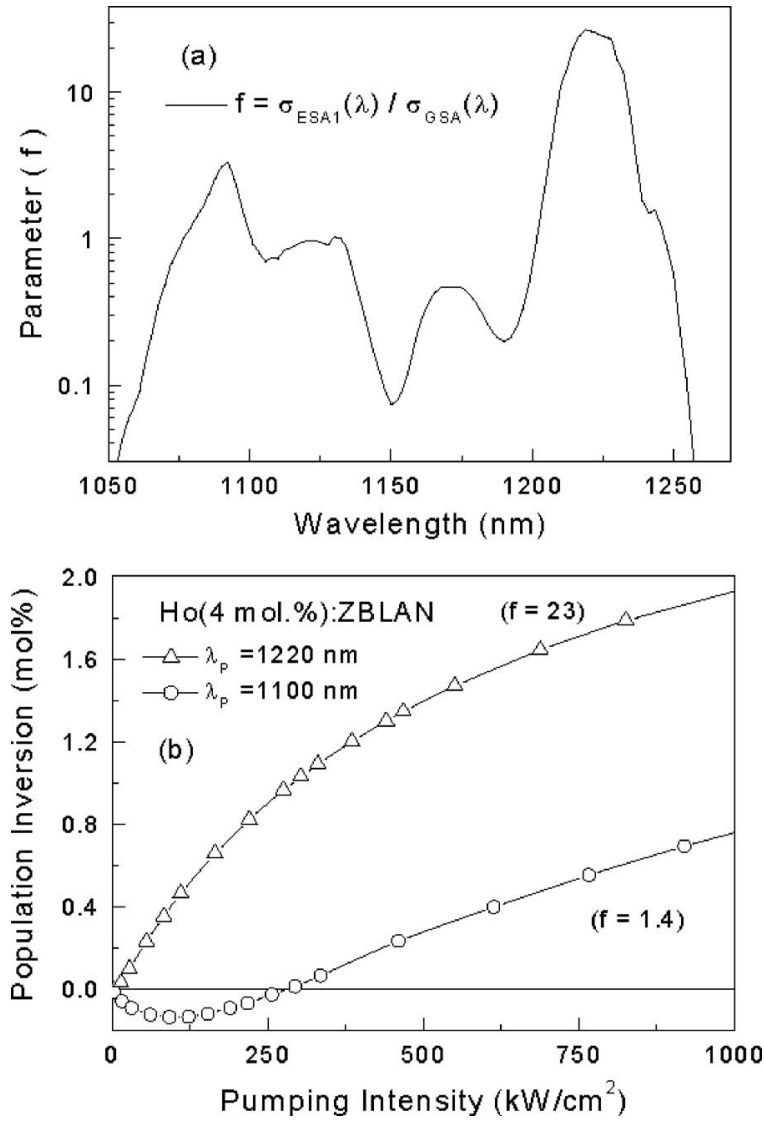

FIG. 8. Calculated (a) cross section ratio $f(\lambda)=\sigma_{\mathrm{ESA} 1}(\lambda) / \sigma_{\mathrm{GSA}}(\lambda)$ as a function of the excitation wavelength and (b) population inversion as a function of the pump rate determined for an excitation wavelength $\lambda_{P}=1095 \mathrm{~nm}$ and $\lambda_{P}=1225 \mathrm{~nm}$ for $\mathrm{Ho}^{3+}(4 \mathrm{~mol} \%)$-doped ZBLAN.

is switched off in the numerical simulation. Thus, ETU1 contributes to the population inversion, but it cannot sustain the population inversion.

Figure 9 shows the results of the numerical calculation of the population inversion for the two $\mathrm{Ho}^{3+}$ laser system cases. The dilute system required a pump intensity of $\sim 6 \mathrm{~kW} \mathrm{~cm}^{-2}$ to produce a zero population inversion which is significantly smaller than the highly doped system ( $\sim 278 \mathrm{~kW} \mathrm{~cm}^{-2}$ ). In addition, the initial slope efficiency of the fiber laser employing dilute $\mathrm{Ho}^{3+}$ concentration fiber was calculated to be $\sim 5.3$ times higher than the slope efficiency relating to the highly doped system, in partial agreement with the reported results. The performance of the fiber laser employing $4.2 \mathrm{~mol} \% \mathrm{Ho}^{3+}$ was strongly affected by the ETU2 process because it has a comparatively larger rate coefficient as determined from our previous investigation. ${ }^{16}$

\section{CONCLUSIONS}

We have isolated and quantified two ESA processes that affect the operation of $\mathrm{Ho}^{3+}$-doped ZBLAN fiber lasers that operate on the $\sim 3 \mu \mathrm{m}{ }^{5} I_{6} \rightarrow{ }^{5} I_{7}$ laser transition when the ${ }^{5} I_{8} \rightarrow{ }^{5} I_{6}$ GSA process is employed. We have established that the phonon sidebands have been important in recent demonstrations of singly $\mathrm{Ho}^{3+}$-doped ZBLAN fiber lasers when the pump wavelength is not resonant with the ESA processes. We calculated the population inversion between the ${ }^{5} I_{6}$ and 


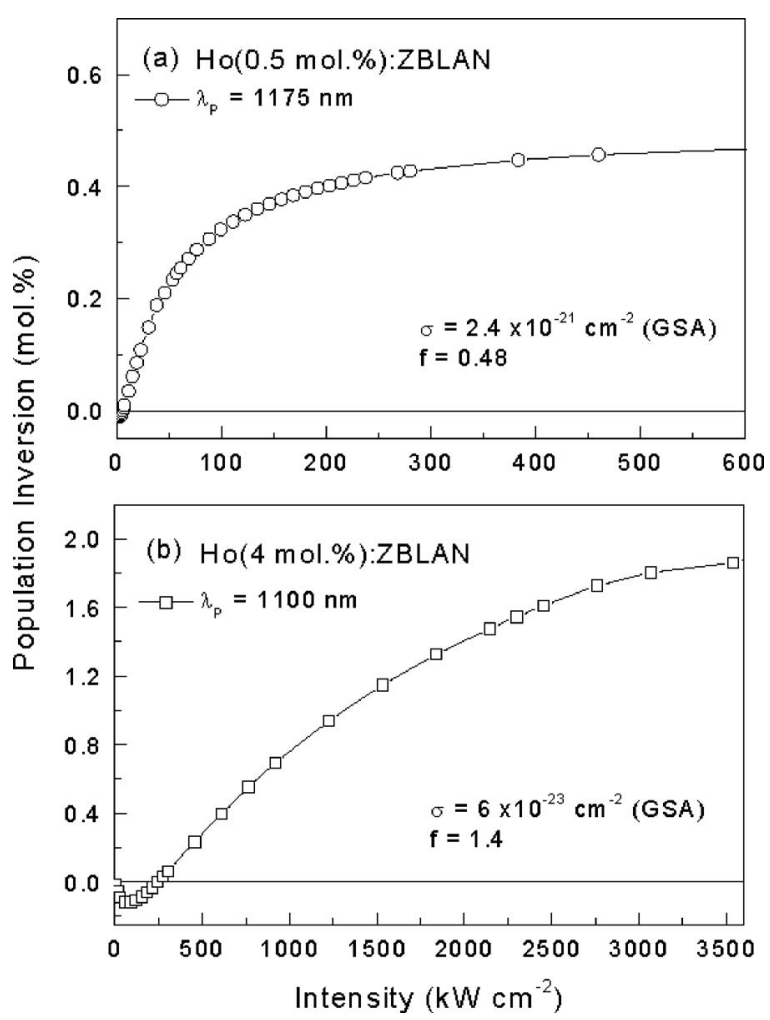

FIG. 9. Calculated steady state population inversion $\left(n_{3}-n_{2}\right)$ as a function of the pump intensity for (a) $\mathrm{Ho}^{3+}(0.5 \mathrm{~mol} \%)$-doped ZBLAN pumped at $1175 \mathrm{~nm}$ and (b) $\mathrm{Ho}^{3+}(0.5 \mathrm{~mol} \%)$-doped ZBLAN pumped at $1100 \mathrm{~nm}$.

${ }^{5} I_{7}$ levels of $\mathrm{Ho}^{3+}$ relevant to two experimental demonstrations of $3 \mu \mathrm{m} \mathrm{Ho}^{3+}$-doped ZBLAN fiber lasers and established that, while the ESA1 process ${ }^{5} I_{7} \rightarrow{ }^{5} I_{4}$ is responsible for allowing a population inversion to take place, in highly concentrated systems, the ETU process ${ }^{5} I_{6},{ }^{5} I_{6} \rightarrow{ }^{5} F_{5},{ }^{5} I_{8}$ seriously impedes the performance. We have shown that the ESA1 process, that depends on the square of the pumping intensity, makes a positive contribution to the population inversion when $K_{\mathrm{ESAl}} \geqslant 0.1 R_{P}$.

\section{ACKNOWLEDGMENTS}

The authors thank financial support from FAPESP (Grant Nos. 1995/4166-0 and 2000/10986-0), CNPq, and the Australian Research Council.

${ }^{1}$ D. Gapontsev, Laser Focus World 41, 9 (2005).

${ }^{2}$ S. Mihashi, G. J. Jako, J. Incze, M. S. Strong, and C. W. Vaughan, Ann. N.Y. Acad. Sci. 267, 263 (1976).

${ }^{3}$ M. L. Wolbarsht, IEEE J. Quantum Electron. 20, 1427 (1984).

${ }^{4}$ M. C. Pierce, S. D. Jackson, M. R. Dickinson, T. A. King, and P. Sloan, Lasers Surg. Med. 26, 495 (2000).

${ }^{5}$ D. K. Killinger, N. Menyuk, and W. E. Defeo, Appl. Phys. Lett. 36, 402 (1980).

${ }^{6}$ A. Mayer, J. Comera, H. Charpentier, and C. Jaussaud, Appl. Opt. 17, 391 (1978).

${ }^{7}$ T. M. Taczak and D. K. Killinger, Appl. Opt. 37, 8460 (1998).

${ }^{8}$ S. D. Jackson, T. A. King, and M. Pollnau, Opt. Lett. 24, 1133 (1999).

${ }^{9}$ B. Srinivasan, J. Tafoya, and R. K. Jain, Opt. Express 4, U10 (1999).

${ }^{10}$ T. Sandrock, D. Fischer, P. Glas, M. Leitner, and M. Wrage, Opt. Lett. 24, 1286 (1999).

${ }^{11}$ S. D. Jackson, Opt. Lett. 29, 334 (2004).

${ }^{12}$ X. S. Zhu and R. Jain, Opt. Lett. 32, 26 (2007)

${ }^{13}$ S. D. Jackson, Electron. Lett. 40, 1400 (2004).

${ }^{14}$ T. Sumiyoshi, H. Sekita, T. Arai, S. Sato, M. Ishihara, and M. Kikuchi, IEEE J. Sel. Top. Quantum Electron. 5, 936 (1999).

${ }^{15}$ S. D. Jackson, Appl. Phys. Lett. 83, 1316 (2003).

${ }^{16}$ A. F. H. Librantz, S. D. Jackson, F. H. Jagosich, L. Gomes, G. Poirier, S. J. L. Ribeiro, and Y. Messaddeq, J. Appl. Phys. 101, 123111 (2007).

${ }^{17}$ R. C. Powell, Physics of Solid-State Laser Materials (Springer-Verlag, New York, 1998), pp. 101-103.

${ }^{18}$ C. Li, Y. Guyot, C. Linarès, R. Moncorgé, and M. F. Joubert, OSA Proc. Adv. Solid-State Lasers 15, 91 (1993).

${ }^{19}$ B. M. Walsh, N. P. Barnes, and B. Di Bartolo, J. Appl. Phys. 83, 2772 (1998).

${ }^{20}$ L. Wetenkamp, G. F. West, and H. Többen, J. Non-Cryst. Solids 140, 35 (1992).

${ }^{21}$ L. V. G. Tarelho, L. Gomes, and I. M. Ranieri, Phys. Rev. B 56, 14344 (1997).

${ }^{22}$ Y. Chen and F. Auzel, J. Non-Cryst. Solids 184, 278 (1995).

${ }^{23}$ D. V. Talavera and E. B. Mejía, Laser Phys. 16, 436 (2006). 